\title{
Temporary Abdominal Closure with Vacuum Pack Technique
}

\author{
Dong Hun Kim \\ Department of Surgery, Trauma Center, Dankook University Hospital, Cheonan, Korea
}

Following severe trauma of the abdomen and pelvis, marked intraabdominal visceral edema, retroperitoneal hematoma, or packing of the peritoneal or pelvic cavity may prevent tension-free abdominal closure, forcing the surgeon to leave the abdomen open. Several techniques of temporary abdominal closure have been reported. We demonstrate a video clip of the vacuum pack technique.

(Trauma Image Proced 2017(1):40-41)

Key Words: Intra-abdominal Hypertension; Resuscitation; Decompression; Abdomen

\section{CASE}

A 43-year-old man underwent ligation of the bilateral internal iliac arteries, suprapubic cystostomy, and reconstruction of the left external iliac vessel for complex pelvic fracture with hemodynamic instability after blunt trauma. The injury severity score was 43 . At the end of the emergency laparotomy, temporary abdominal closure with a vacuum pack technique was performed due to marked visceral edema, retroperitoneal hematoma, and packing of the pelvic cavity (Video. 1). Reexploration was planned and primary fascial closure was achieved 42 hours after damage control surgery.

\section{DISCUSSION}

After completion of the abdominal surgery, JacksonPratt drains are placed in the peritoneal cavity. As the
45 x $60 \mathrm{~cm}$ Ioban Antimicrobial Incise Drape (3M, St Paul, MN) or polyethylene sheets prepared, dry surgical towels are placed over the adhesive aspect of the Ioban drape adjusting to the range of the open abdomen. The visceral aspect of the Ioban drape is perforated multiple times with a scalpel blade. It then is placed over the peritoneal viscera and beneath the peritoneum of the abdominal wall. Experientially, towels attached to the Ioban drape seem to be easy to locate and be less broken away during placement in the open abdomen. Next, two Jackson-Pratt drains are placed on top of the towels, and the tubing is tunneled along the subcutaneous tissue to exit approximately 3 to $5 \mathrm{~cm}$ away from the upper or middle side of the wound. Then, the same-sized Ioban drape is placed over the wound and adjacent abdominal wall skin after adjacent skin is dried with towels. Each drain tube is connected to bulb suction. Finally, temporary abdominal closure is checked

Received: March 28, 2017 Revised: April 7, 2017 Accepted: April 11, 2017

Correspondence to: Dong Hun Kim, Department of Surgery, Trauma Center, Dankook University Hospital, 201 Manghyang-ro, Dongnam-gu, Cheonan 31116, Republic of Korea

Tel: 82-41-550-7661, Fax: 82-41-550-0039, E-mail: saint7331@gmail.com

Copyright (c) 2017 Korean Association for Research, Procedures and Education on Trauma. All rights reserved.

(c) This is an open-access article distributed under the terms of the Creative Commons Attribution Non-Commercial License (http://creativecommons.org/ licenses/by-nc/4.0) which permits unrestricted noncommercial use, distribution, and reproduction in any medium, provided the original work is properly cited 
to determine whether the negative pressure seal is completed $(1,2)$

\section{Conflict of Interest Statement}

No potential conflict of interest relevant to this article was reported.

\section{REFERENCES}

1. Barker DE, Kaufman HJ, Smith LA, Ciraulo DL, Richart CL, Burns RP. Vacuum pack technique of temporary abdominal closure: a 7-year experience with 112 patients.
Journal of Trauma and Acute Care Surgery. 2000;48(2): 201-7.

2. van Hensbroek PB, Wind J, Dijkgraaf MG, Busch OR, Goslings JC. Temporary closure of the open abdomen: a systematic review on delayed primary fascial closure in patients with an open abdomen. World journal of surgery. 2009;33(2):199-207.

\section{Video Legend}

Video 1. An intraoperative video recording shows a sequence of temporary abdominal closure with vacuum pack technique at the end of the emergency laparotomy. 